\title{
Los impedimentos para responsabilizar penalmente a las empresas transnacionales por daños ambientales en Colombia ${ }^{*}$
}

\author{
Omar Huertas Díaz \\ Iván Ricardo Morales Chinome
}

Recibido: 5 de abril de 2015 • Revisado: 10 de mayo de 2015

Aprobado: 20 de mayo de 2015

\section{Resumen}

A causa de los problemas ambientales que las empresas transnacionales generan en el mundo y la falta de responsables, y aunque si bien es cierto no está empíricamente demostrada la función disuasiva de la pena, el derecho penal ambiental, como una manifestación del derecho penal moderno (diferente del derecho penal liberal clásico) se ha erigido como una herramienta (pero no efectiva) para el control y el castigo por la degradación ambiental de las empresas transnacionales, para lo que sería necesario comenzar por examinar la naturaleza, la normatividad y

"Este artículo es resultado de la investigación del Grupo de Investigación "Escuela de Derecho Penal Nullum Crimen Sine Lege UN”. Financiado por la Universidad Nacional de Colombia, actualmente registrado con el Código COL0078909 en Colciencias, reconocido y clasificado en D.

"* Profesor asociado facultad de Derecho, Ciencias Políticas y Sociales, Universidad Nacional de Colombia. Candidato a doctor en Derecho de la Universidad Nacional de Colombia. Magíster en Derecho Penal de la Universidad Libre. Candidato a doctor en Ciencias de la Educación de la Universidad Simón Bolívar. Magíster en Derechos Humanos, Estado de Derecho y Democracia en Iberoamérica de la Universidad de Alcalá, España. Magíster en Educación de la Universidad Pedagógica Nacional y de la Universidad Nacional de Colombia. Profesor asociado, especialista en Derecho Penal y socio de la Fundación Internacional de Ciencias Penales FICP. Miembro de honor de la Fundación de Victimología. Correo electrónico: ohuertasd@unal.edu.co

*** Magister en Derecho con profundización en Sociología y Política Criminal de la Universidad Nacional de Colombia. Abogado de la Universidad Nacional de Colombia. Investigador Observatorio de Política Criminal en Colombia, e investigador Grupo de Investigación Escuela de Derecho Penal Nullum crimen sine lege de la Universidad Nacional de Colombia. Correo electrónico: irmoralesc@unal.edu.co 
las actuaciones de estas compañías, y determinar las razones que vuelven el actual derecho penal ambiental insuficiente para ejercer un control efectivo sobre ellas.

Palabras clave: daños ambientales, derecho penal moderno, empresas transnacionales.

\title{
IMPEDIMENTS FOR HOLDING TRANSNATIONAL CORPORATIONS CRIMINALLY LIABLE FOR ENVIRONMENTAL damages in Colombia
}

\begin{abstract}
Because of the environmental problems that transnational companies generate in the world and the lack of responsibility, and even if it is true is not empirically proven deterrent function of punishment, the environmental criminal law, as a manifestation of criminal law modern (different from the classical liberal criminal law) has emerged as one (but ineffective) tool to control and punishment by environmental degradation of transnational corporations, so it would be necessary to begin by examining the nature, regulations and performances of these companies, and determine the reasons which make the current environmental criminal law insufficient to exercise effective control over them.
\end{abstract}

Keywords: Environmental damage, modern criminal law, transnational corporations.

\section{OS IMPEDIMENTOS PARA RESPONSABILIZAR \\ PENALMENTE AS EMPRESAS TRANSNACIONAIS POR DANOS ambientais na Colômbia}

\section{Resumo}

Por causa dos problemas ambientais que as empresas transnacionais geram no mundo e a falta de responsáveis, e até mesmo que não está empiricamente comprovada à função dissuasora da punição, o direito penal ambiental, como uma manifestação do direito penal moderno (diferente do direito penal liberal clássico) tem surgido como uma ferramenta (mas não eficaz) para o controle e a punição pela degradação ambiental das empresas transnacionais, de modo que seria necessário começar por examinar a natureza, os regulamentos e as ações de essas companhias, e determinar 
as razões pelas quais o direito penal ambiental vigente é insuficiente para exercer controle efetivo sobre elas.

Palavras-chave: Danos ambientais, direito penal moderno, empresas transnacionais.

\section{Introducción}

El concepto que se ha dado a la empresa multinacional (EMN) o transnacional puede ser dividido de la siguiente forma: en un concepto económico, con base en el cual se dirá que es una unidad de producción orientada por un carácter organizacional corporativo y con tendencia expansionista en el ejercicio de sus actividades, y en un concepto jurídico, con base en el cual tendrá que adecuarse a las formas empresariales, corporativas o societarias consagradas en cada ordenamiento nacional, para el ejercicio de actividades económicas o industriales, siendo, además, un elemento que servirá para la determinación de la jurisdicción a la que podrá acudirse para reclamar por los daños causados en desarrollo de su actividades (Teitelbaum, 2007).

La EMN tiende a ser una empresa oligopólica en la cual la propiedad, el manejo, la producción y las actividades de venta se extienden a través de diversas jurisdicciones nacionales. Comprende una oficina principal en un país y un conjunto de subsidiarias en otros países. El objetivo principal de la empresa es asegurar la producción menos costosa posible de bienes para los mercados mundiales; esta meta puede alcanzarse adquiriendo los emplazamientos más eficientes para los mecanismos de producción y obteniendo concesiones impositivas por parte de los gobiernos anfitriones (Gilpin, 1990).

Generalmente, como dijo la Corte de Justicia de las comunidades Europeas en 1986 (caso 270/83), una sociedad transnacional está constituida por una sociedad matriz creada de conformidad con la legislación de un país determinado, que se implanta en otros países mediante inversiones directas, sin crear sociedades locales o mediante filiales que se constituyen como sociedades locales, de conformidad con la legislación del país huésped (Rigaux, 1991).

Ante el surgimiento de las empresas como formas de organización privada que se contraponen a la organización estatal, se hace necesario empezar a considerarlas, como sujetos jurídicos a quienes puede imputarse la responsabilidad por los daños o perjuicios ocasionados en desarrollo de actividades económicas o industriales que 
realizan, pues las sociedades transnacionales, son personas privadas con personalidad jurídica nacional.

\section{Transnacionales y soberanía estatal}

Las empresas transnacionales a finales del siglo XX se han constituido en una amenaza para la soberanía de los Estados. Por eso, el primer aspecto en el que se ha fijado la controversia en cuanto al poder que pueden ostentar tales empresas y la soberanía de los Estados, lo constituyen las diferencias de comportamiento que presentan las transnacionales y sus efectos respecto del bienestar económico nacional, que en ocasiones ha producido una actitud de desconfianza por parte de los Estados en donde se instalan o establecen.

En ese sentido, existe actualmente un Código de Conducta para las empresas transnacionales, aprobado por la Asamblea General de las Naciones Unidas, que contiene tres supuestos con base en los cuales estas empresas deben respetar la soberanía de los Estados; en ellos se cita:

1. Las empresas transnacionales respetarán la soberanía nacional de los países en que funcionen, así como el derecho de cada Estado a ejercer su soberanía permanente sobre su patrimonio y sus recursos naturales.

2. Las entidades de las empresas transnacionales están sujetas a las leyes, los reglamentos y las prácticas administrativas establecidas de los países en que funcionen.

3. Las empresas transnacionales respetarán el derecho de cada Estado a regular y supervisar en la forma correspondiente las actividades de las entidades de las empresas de esa índole que funcionan en su territorio.

Pese a que en el orden normativo internacional existen supuestos como los vistos, se percibe un gigantismo empresarial ante lo cual los Estados, según la tendencia que se imponga, han adoptado medidas económicas intervencionistas en aquellos sectores más susceptibles a la vulneración de intereses o derechos colectivos, respecto de los cuales es deber de las administraciones públicas defenderlos (imposición en su mayoría que deriva de las Cartas Políticas de cada estado) y con ello tratando de dar un equilibrio entre los intereses particulares de las empresas multinacionales y los intereses públicos generales (entre ellos los colectivos) de los ciudadanos de los Estados. 
Por otra parte, algunos autores, como Paul Streeten, manifiestan que existen "cuatro causas de conflicto entre la multinacional o transnacional y el gobierno receptor": el hecho de que la empresa sea privada, por lo que podrá existir conflicto con las metas sociales y nacionales proyectadas por los gobiernos de los estados receptores; el tamaño de la misma y su tendencia oligopólica; su origen extranjero que dificulta el ejercicio de la jurisdicción del país receptor, en relación con las empresas matrices, en aquellos casos en que se vean enfrentados derechos sociales colectivos (e incluso fundamentales) con los intereses económicos de dichas empresas, y la implantación y desarrollo de tecnologías que puedan afectar a comunidades que no estén preparadas para cambios intempestivos tanto en sus costumbres como en su forma de vida, debido a las nuevas formas de producción, los nuevos productos, y los nuevos procesos industriales que deterioran el entorno ambiental de esas comunidades, con la de que en aquellas zonas menos desarrolladas es difícil realizar los procesos de depuración y limpieza por no poder contar con todos los instrumentos necesarios (Teitelbaum, 2007).

Sin embargo uno de los conflictos recurrentes de las empresas transnacionales es de orden normativo al que deben someterse estas empresas. En los últimos años, los aspectos que han generado los mayores conflictos entre las actividades de tales empresas y la soberanía de los Estados son: el ambiente (en especial lo relacionado con la responsabilidad por afectación al ambiente que se les imputaría como producto de las actividades que desarrollen) y las operaciones industriales y económicas de la empresa transnacional en diferentes territorios (lo que ha puesto difícil la determinación de la jurisdicción que podría acometer el conocimiento de los casos en los que se observen infracciones a normas no sólo de protección al medio ambiente, sino también en otras materias).

Por ejemplo en la práctica, el conflicto normativo y de soberanía se expresa en relación con la jurisdicción aplicable, respecto de lo que encontramos que en Estados Unidos el Tribunal del Distrito de Nueva York tiene una serie de precedentes en la misma, fijando la siguiente posición jurídica: tiene jurisdicción el Tribunal de Nueva York en casos en que se encuentren involucradas empresas internacionales (transnacionales), cuando exista una afectación bien sea directa o indirecta respecto del Estado norteamericano o de sus ciudadanos, como se estudió en el caso de la fábrica de químicos en Bhopal (India).

El principio de la soberanía comprende, también, la determinación de la jurisdicción procedente. En ese sentido, el problema más complejo de resolver 
respecto de la situación jurídica de las empresas transnacionales lo constituye la falta de una jurisdicción internacional (y la incipiente aplicación del criterio de jurisdicción universal) a la que debieran sujetarse, lo que ha permitido que hasta la fecha se presenten, en muchos países en desarrollo, fenómenos como la hegemonía, la corrupción, la injusticia, la contaminación y la indiferencia hacia los intereses de los ciudadanos y consumidores, lo que requiere la toma de medidas por parte de los Estados, entre las que se pueden mencionar: establecimiento de un código de conducta (efectivo) en derecho internacional, en el que se concreten los procedimientos, instancias y acciones que puedan invocarse contra sujetos privados, como las empresas multinacionales o transnacionales, por la infracción de normas tanto internacionales como nacionales; de igual forma, debe considerarse el reconocimiento de personalidad jurídica internacional a los sujetos privados, en especial a aquellos que participan en la economía mundial (empresa), y si es el caso realizar las enmiendas correspondientes al Código de conducta para las empresas transnacionales de las Nacionales Unidas, aprobado en 1988.

En el caso específico del ambiente, las controversias en las que participan como responsables de su afectación las empresas transnacionales han sido dirimidas en su mayoría, por medio del arbitraje (mecanismo de solución de conflictos más utilizado en el derecho internacional público contemporáneo), consistente en arreglos amistosos o simples regateos en relación con la cuantía de las indemnizaciones. No obstante, la anterior solución ha transformado en ilusorios los derechos de la comunidad internacional a una vida saludable y productiva en armonía con la naturaleza, como quedó consagrado en el principio número 1 de la Declaración de Río de Janeiro de 1992. De igual forma, la posibilidad de llevar casos en los que esté comprometida la responsabilidad de las transnacionales por afectación al medio ambiente ante la Corte Internacional de Justicia de la Haya $\mathrm{u}$ otros organismos internacionales que se creen, es prácticamente nulo, lo que ha generado un desfase que no ha podido ser atendido por las jurisdicciones nacionales (Teitelbaum, 2007).

Además, a favor de las transnacionales operan mecanismos de impunidad preestablecidos por estas y los Estados, que tienen que ver con la ausencia de verdaderos escenarios de justicia, como son la ineficacia de los códigos obligatorios, la creación de códigos voluntarios, la falta de jurisdicción competente y su personalidad jurídica de derecho civil y comercial. 


\section{Normas obligatorias específicas para las sociedades transnacionales}

Los principales intentos de crear un marco jurídico internacional específico obligatorio para las sociedades transnacionales (código de conducta y código sobre transferencia de tecnología) no han tenido éxito.

Solamente la Declaración de Principios Tripartita sobre las sociedades transnacionales y la Política Social de la Organización Internacional del Trabajo -cuyos mecanismos de seguimiento de la OIT intenta actualizar y reforzar-, y algunos otros instrumentos no obligatorios, como las "directrices" de la OCDE (1976, reformadas en 1979, 1984 y 2000), el conjunto de principios para el control de las prácticas comerciales restrictivas, aprobado por la Asamblea General de las Naciones Unidas (resolución 3563, etc.). En el plano regional los países del Pacto Andino, mantuvieron durante cierto tiempo (decenio de 1970) un cuadro jurídico bastante completo respecto de las sociedades transnacionales, particularmente la Decisión 24 del Acuerdo de Cartagena, pero después dichas normas se flexibilizaron considerablemente.

\section{Códigos voluntarios y controles privados}

Cuando a fines del decenio de 1980 se abandonó el proyecto de un Código Internacional de Conducta para las Sociedades Transnacionales, las Sociedades Transnacionales se sintieron enteramente libres para actuar con la exclusiva finalidad de obtener beneficios máximos, y con total desprecio de los derechos humanos y ambientales.

Se implantó en 1990 la elaboración para sí mismas, a veces con la intervención exterior de ONG de Códigos de Conducta Propios. Levi Strauss, Nike y Reebok, por ejemplo, elaboraron sus propios códigos de conducta, como reacción a las campañas (Clean Clothes y otras) sobre las condiciones de trabajo deplorables existentes en los lugares de producción, localizados en países pobres (Ibídem).

Pero ocurre que en la práctica los códigos de conducta no se aplican en esos lugares de producción, porque a menudo estas grandes sociedades transnacionales no son empresas productoras, pues subcontratan la producción, externalizando así los costos y los riesgos. 


\section{La sociedad entre grandes organizaciones no gubernamentales y las transnacionales}

A la exigencia de un control externo realmente independiente, las sociedades transnacionales responden contratando auditorias de grandes consultoras transnacionales (con resultados delictuosos hechos públicos en el 2002), o aceptando pseudo controles de ONG más o menos complacientes, que oscilan entre el control y el asesoramiento (de preferencia directa o indirectamente remunerado de dichas sociedades) (Corte Interamericana de Justicia, 1949).

Las sociedades transnacionales son los principales beneficiarios de este "control independiente practicado por ciertas ONG", pues así se dan una buena imagen pública y logran evitar verdaderos controles exteriores públicos y obligatorios.

En conclusión, los códigos de conducta voluntarios son iniciativas privadas y, por tanto, ajenos a la actividad normativa de los Estados, de cumplimiento obligatorio y a la actividad normativa (convenios, resoluciones, declaraciones, etc.) o iniciativa para promover nuevas normas o la aplicación consecuente de normas ya existentes (directrices, declaraciones de principios, etc.) de las organizaciones internacionales interestatales. Sin embargo, la práctica ha demostrado que dichos códigos de conducta voluntarios son ineficaces (Teitelbaum, 2007).

\section{Responsabilidad jurídica de las empresas transnacionales}

Se excluye a las personas, entre ellas a las sociedades transnacionales del marco jurídico de los derechos humanos, estas quedan sometidas solo al derecho interno común, que es manifiestamente insuficiente para llegar a responsabilizarlas, y eventualmente sancionarlas.

Ello es así porque en los países centrales las sociedades transnacionales cuentan con una legislación favorable y, sobre todo, con el respaldo incondicional de los gobiernos. Y en los países periféricos del sistema pueden violar las normas internas o hacerlas reformar en su propio interés y, por cierto, pueden también violar los derechos humanos con la complicidad de las élites dirigentes de muchos de esos países y así asegurar su impunidad (Ibídem).

Esto unido a la extrema fluidez de movimientos transfronterizos de las transnacionales, sobre todo su capital financiero pero también de su capital fijo, que les 
permiten eludir el cumplimiento de las leyes y los reglamentos nacionales, hacen manifiestamente insuficientes las legislaciones internas y exige la aplicación de los procedimientos y mecanismos internacionales de derecho público existentes, y la creación de otros más eficaces que obligue a estas empresas a respetar los derechos laborales y ambientales y la sujeten a sanciones en caso de incurrir en su violación.

Más específicamente, en la materia ambiental cuando las actividades de las personas (físicas y jurídicas) de derecho privada son internacionales, pueden cometer delitos internacionales (delito transnacional, es decir, a través de las fronteras). Incluso, cuando dichas actividades se desarrollan en un ámbito nacional sin trascender las fronteras, pueden dar lugar a la comisión de crímenes internacionales.

Las sanciones penales contra las personas jurídicas pueden ser la multa, la difusión pública de la decisión condenatoria, la confiscación del instrumento o de su producto, y la disolución. La condena debe incluir la obligación de reparar el daño.

La responsabilidad penal de las personas jurídicas no excluye la de las personas físicas, integrantes del órgano competente que, con su voto afirmativo o por omisión, contribuyeron a la adopción de la decisión o de las decisiones incriminadas.

\section{Las jurisdicciones competentes}

Dada la ausencia de instancias internacionales que hagan directamente justiciables las actividades jurídicas privadas, las violaciones cometidas por aquellas solo pueden ser objeto en el plano internacional, a través de la responsabilidad subsidiaria de los Estados.

En el ámbito nacional, la actividad jurisdiccional puede y debe ejercerse plenamente con relación a los particulares, incluidas las sociedades transnacionales, aplicando el derecho nacional y las normas internacionales vigentes en el derecho interno.

Los tribunales competentes para este tipo de demandas pueden ser el lugar donde se produjo el daño, o el de la sede principal de la sociedad transnacional que provocó el daño.

Sin embargo, en ciertas jurisdicciones existe el principio discrecional forum non conveniens, que se utiliza frecuentemente para eludir o disminuir la responsabilidad de la casa matriz cuando esta es objeto de una denuncia ante los tribunales de su domicilio principal, a causa de actividades ilegítimas realizadas por una filial en el ámbito de otra jurisdicción, como ejemplo tenemos la Transnacional Francesa 
TOTAL que quedó excluida de la causa ante los tribunales estadounidenses porque prosperó su defensa de incompetencia de jurisdicción.

\section{Los daños ambientales y el derecho penal ambiental}

Una de las modificaciones más dramáticas de la degradación del ambiente es el cambio climático, resultado de una multitud de causas que interactúan entre sí, algunas naturales y otras originadas en la actividad humana. Esta última influye cada vez más en dicho cambio como consecuencia de la irracionalidad del modelo económico dominante fundado en la ganancia máxima para un puñado de gigantescos grupos económicos que fomentan y promueven una cultura consumista (transnacionales), y del despilfarro en el sector de la población mundial que tiene un nivel de ingresos suficiente para adoptarla.

En efecto, hace ya tiempo que la deforestación está produciendo daños incalculables, que industrias contaminantes (muchas de ellas de los países desarrollados a los países del Tercer Mundo) envenenan la atmósfera, el agua y la tierra, y que enormes cantidades de desechos tóxicos son también exportados de los países industrializados a los países menos avanzados (Ibídem).

La deforestación, es una importante causa concurrente a la degradación ambiental. Se pueden dar numerosos casos, además del bien conocido de la Amazonía.

\section{El derecho penal moderno, ¿una herramienta efectiva?}

Luis Gracia Martín entiende por derecho penal moderno:

El conjunto integrado por las nuevas figuras delictivas añadidas a las legislaciones penales y por las modificaciones -o agravaciones- de las tradicionales, con el fin, en todos los casos, de extender la intervención penal a conductas y ámbitos de la realidad social del presente que estaban excluidos de la punibilidad en el sistema tradicional de la parte especial, o bien, en su caso, para dispensar a determinados hechos tradicionalmente punibles con tratamiento penal más severo cuando concurren determinadas circunstancias a las que en el presente se atribuyen significados especialmente relevantes desde el punto de vista penal (Gracia Martín, 2003, p. 58). 
Y como manifestaciones particulares del derecho penal moderno, aparecen la criminalidad empresarial (derecho penal de la empresa), al derecho penal de la globalización, el derecho penal de los estados miembros de la Unión Europea orientado a la protección de bienes jurídicos europeos, al futuro derecho penal europeo, y finalmente, al denominado derecho penal del enemigo (Ibídem, p. 59).

Según este autor, la manifestación más destacada e importante del derecho penal moderno es el derecho penal económico y del medio ambiente, este tipo de delincuencia, es practicada especialmente por la clase alta y media que se relaciona sobre todo con actividades económicas y de los negocios.

El derecho penal del medio ambiente no solo es el sector por excelencia el derecho penal moderno, sino también el campo en que se desarrolla de modo preferente y especialmente intenso la polémica actual sobre la modernización del derecho penal (Ibídem, p. 80).

Los delitos económicos y medioambientales, salvo excepciones completamente marginales, suelen tener la condición de especiales en razón de que los hechos únicamente pueden ser cometidos de modo típico, es decir, en concepto del autor, por un círculo de sujetos cualificados por determinadas condiciones personales especiales, como por ejemplo, y según los casos, las de comerciante, exportador, empleador, obligado tributario, etc., por tanto el fundamento material de los delitos especiales está en la especial posición y capacidad de dominio (social) de estos sobre el ámbito social en que se hayan determinados bienes jurídicos, que solo se encuentran necesitados de protección penal frente a determinadas acciones típicas de esos sujetos con dominio social, y no frente a las de quienes carecen de dicho dominio (Ibídem, p. 84).

Puesto que según él, el derecho penal moderno ha dejado de proteger exclusivamente en forma de bienes jurídicos los derechos y privilegios de una clase social (anteriormente la burguesía), para proteger bienes colectivos como el medio ambiente que pertenecen a otras clases sociales.

Hoy la mayor parte de la actividad económica y, correspondientemente, la actividad delictiva económica de hecho solo es imaginable y posible por parte de la organización de un conjunto de medios y de personas en la forma de una empresa, y por ello en el ejercicio de una actividad típicamente empresarial o en relación con ella.

Sin embargo, a pesar que el derecho penal de la empresa y ambiental constituye un sector individualizado de la parte especial del derecho penal, su problemática 
más grande se encuentra en la imputación jurídico penal, y por consiguiente, en la parte general. El moderno derecho penal de la empresa plantea, sin duda, a la ciencia penal del presente uno de sus retos más importantes.

Puesto que más allá de las cuestiones político-criminales que suscita el mismo en el ámbito de la parte especial, los problemas que plantean en el plano de la imputación constituyen un duro blanco de pruebas para la validez, sobre todo una teoría general de la responsabilidad penal (sc., del delito) que como la hasta ahora vigente, se ha construido sobre la base de un modelo de criminalidad violenta e individual. Esta, apenas tiene algo en común con el modelo de la nueva criminalidad económica empresarial que se desarrolla en contextos de actividad colectiva realizada por una pluralidad de sujetos que actúan de acuerdo con el principio de la división del trabajo de funciones y en posiciones de supra y subordinación jerárquica (Ibídem, p. 84).

Por ello, la necesidad de hacer frente a este tipo de criminalidad con el derecho penal ha puesto en jaque a casi todos los instrumentos dogmáticos tradicionales y, desde luego, convertido ya en obsoleta a la parte general tradicional de nuestra disciplina en la medida en que los conceptos estructurales desarrollados por la misma se proyectan solo a campos de realidad social muy reducidos y en que, por ello mismo, en principio, aquellos no pueden ofrecer ninguna respuesta segura a los problemas de imputación que plantea el derecho penal moderno en general, y de la empresa en particular, como una de las manifestaciones más destacadas de este (Ibídem, p. 88).

\section{Derecho penal ambiental en Colombia}

Si bien es cierto no está empíricamente demostrada la función disuasiva de la pena, y siendo precaria la conciencia ambiental, es utópico pretender que la disposición de castigos del aparato punitivo mitigue por sí solo los efectos anti ecológicos e inviertan los valores de la gestión ambiental de la cultura dominante hacia una convivencia pacífica con la naturaleza.

Los sistemas penales del tercer mundo, agobiados de trabajo y deprimidos por carencias logísticas y presupuestales, se ocupan preferentemente del juzgamiento de delitos como el homicidio, el terrorismo, narcotráfico, el hurto, etc. Y dejan un espacio exiguo para la protección del ambiente, que es tema marginal desde el punto de vista académico (desconocimiento o relevancia mínima en el pensum de las 
escuelas de leyes), social (las clases hegemónicas son refractarias a ceder privilegios), legal (pocos códigos penales protegen el ambiente) y dogmático (los estatutos que amparan el entorno abundan en contradicciones y vacíos, por ejemplo no protegen los derechos ambientales en sí sino los bienes patrimoniales que se afectan, a lo que se agrega trabas procesales insalvables que llevan a una descriminalización de facto y una despenalización de jure (Ramírez, 2007).

Y si están deficientemente equipados para investigar la delincuencia convencional, más lo estarán para hacer esta especie delictiva que requiere de especialización técnica y material, constituyéndose en pesadas cargas para el establecimiento y entonces la protección penal será pura apariencia. Pero en la gran búsqueda de cambios radicales en la conciencia individual y colectiva, se guardan grandes esperanzas de contribución decidida en el mecanismo de control social de esta alternativa que inclusive puede ofrecer la seria posibilidad ayudar a la democratización de la aplicación de la ley (Ibídem, p. 178).

El proceso de criminalización se integra de dos etapas: primero, génesis de la protección del medio ambiente como tarea sociopolítica; y segundo, génesis del derecho penal para la protección del medio ambiente como instrumento específico de política ecológica y criminales.

Sin embargo, en la creación de la norma el derecho penal ambiental han tenido gran influencia sus destinatarios, de gran poder social y económico y de gran capacidad organización y conflicto, a saber: firmas, empresas industriales, sobre todo productoras de instalaciones técnicas y funcionarios y autoridades administrativas que otorgan los permisos y ejercen el control de tales instalaciones.

Está demostrado que la influencia de estos grupos en la elaboración de la norma y la prevalencia de sus intereses ha sido muy notoria, al contrario de los destinatarios de la norma penal clásica que son impotentes tanto en el nivel de elaboración como de ejecución. Existen tipos penales consagrados para sancionar a los usuarios finales de productos y tecnologías potencialmente contaminantes, pero no a los diseñadores y productores de los mismos, y poca atención se presta a que las clases subalternas participan en las prácticas anti ecológicas como actores dramáticos de la pobreza absoluta. Este es, definitivamente, un crimen de poderosos que reclama una escrupulosa aplicación del control social institucional o de los mecanismos de selección secundaria, para remediar el carácter selectivo de la norma puesto de manifiesto, además, con el tratamiento legislativo diferencial de las conductas que afectan derechos particulares y derechos comunitarios (Ibídem, p. 179). 


\section{Caracterización del derecho penal ambiental}

Hoy está superada la discusión en torno a la legitimidad de la intervención del derecho penal en los temas referidos a los recursos naturales y el medio ambiente, pues las legislaciones de la totalidad de los estados y los teóricos están acuerdo en que estamos ante un bien jurídico digno, necesitado y merecedor de protección penal (Ibídem, p. 195).

Lo que sí se discute es lo relativo a la manera, es el cuándo, el cómo y bajo qué condiciones resulta acorde con los postulados garantistas y los criterios de eficacia la utilización de ius puniendi y, no solo para establecer lo que se debe prohibir sino señalar a la hora de perseguir los infractores, como se debe sancionar (Ibídem, p. 196).

En todo caso, el carácter preventivo del derecho penal es un elemento esencial en la legitimación de la utilización de este medio de control social en contra de los agresores del bien jurídico.

En cuanto a la protección del medio ambiente en Colombia, la realidad es inequívoca: la experiencia en la aplicación es lamentable, pues a pesar de las evidencias cotidianas que nos muestran los estragos que se producen contra los recursos naturales y el medio ambiente, la cantidad de procesos penales abiertos para perseguir a los escocidas es reducida y el número de condenas ejecutoriadas es ínfimo (Ibídem, p. 196).

En los últimos tiempos se ha incrementado el número de legislaciones que regulan esos delitos en sus códigos penales. Sin embargo esta situación no es por sí misma ni buena ni más efectiva, aunque lo lógico es que los asuntos que se refieren al derecho penal deben aparecer en el código correspondiente.

De acuerdo a todo lo anterior, la gran dificultad que tiene el derecho penal moderno es que si bien en la gran mayoría de legislaciones están consagrados los tipos penales ambientales en la parte especial, la parte general fundada en los principios del derecho penal liberal clásico es insuficiente para imputar la responsabilidad a las trasnacionales que están constituidas como personas jurídicas.

Así pues, en el derecho penal colombiano la discusión se ha centrado principalmente en la forma de imputación de las empresas transnacionales, por cuanto son personas jurídicas, no personas naturales, por lo tanto es imposible atribuirles alguna responsabilidad penal, sin embargo los daños ambientales producto de sus actividades económicas son reales. 


\section{La responsabilidad penal de las personas jurídicas en Colombia}

Las actividades socialmente dañosas en cuya participación intervienen las personas jurídicas y que han representado grandes catástrofes de ambientales, como la fuga de gas en Bhopal en 1976, que dejó cerca de 4.000 muertos y más de 300.000 lesionados; los escapes producidos en uno de los reactores nucleares de Chernóbil (1986), con 25 muertes inmediatas y más de 150.000 personas lesionadas con consecuencias irreversibles; el desastre del Exxon Valdez (1989), cuando se vertieron grandes cantidades de petróleo al mar, que contaminan más de $1.600 \mathrm{~km}$ de la cosa Alaska; el hundimiento del petrolero Pesstigge (2002), que contaminó las aguas de la península ibérica, entre las más significativas, así como muchas actividades fraudulentas de las empresas en el ámbito económico, llevan permanentemente a los legisladores y los teóricos a examinar la posibilidad de disciplinar con penas criminales a los entes colectivos, ya que parecen insuficiente las sanciones administrativas y civiles (Ibídem, p. 202).

Es bien conocido que en el campo internacional son los Estados y las compañías trasnacionales, y en materia interna es el Estado y otras personas jurídicas, los principales agentes de contaminación ambiental.

En la doctrina penal desarrollada en el marco del sistema jurídico de raigambre continental europeo, no ha existido asomo de acuerdo en torno a la existencia o no de responsabilidad penal de las personas jurídicas. Las posiciones van desde aquellos que siempre se han opuesto a la criminalización de las actividades antijurídicas de los entes colectivos, que hasta ahora han sido la mayoría, pasando por los que piensan que tales actos podrían conllevar solamente mediadas de seguridad administrativas o simplemente consecuencias accesorias a las penas, y aquellos que demandan la construcción de un marco teórico y legislativo para criminalizar sus acciones, hasta los que se declaran abiertamente partidarios de convertir en sujetos activos del derecho penal a las organizaciones o empresas (Ibídem, p. 203).

Destacadas voces de la doctrina se vienen pronunciando sobre la necesidad de establecer un sistema de penas aplicables a las personas jurídicas. En la actualidad las legislaciones de Inglaterra, Dinamarca, Holanda, Suecia, Portugal, Noruega, Canadá, Puerto Rico, Brasil y Francia, para citar los estados más importantes, han dado visto bueno a la aplicación de la ley penal a las personas jurídicas. 
Algunos autores de clara estirpe funcionalista promueven la responsabilidad penal de las personas jurídicas con el propósito de forzarlas a la adopción de medidas efectivas que impidan las lesiones contra los bienes jurídicos. Tal responsabilidad la erigen a partir de la infracción o vulneración de deberes que se realiza ante una carencia en la organización o en la ética empresarial que se traduce en comportamientos lesivos contra los bienes jurídicos, siendo el dolo o la imprudencia presupuesto de la punibilidad (Ibídem, p. 217).

Sin embargo, la doctrina más autorizada en Colombia no ha aceptado que los entes colectivos son responsables penalmente, aunque no han faltado voces aisladas defendiendo tal postura.

\section{La corte constitucional y el derecho penal ambiental}

El legislador nacional, en la ley 491 de 1999, por la cual se implantó el seguro ecológico y se modificó el código penal de 1980, consagró en su artículo 26, que adicionó el artículo 247 el código penal, que en los eventos de las conductas punibles de incendio, daño de obras de defensa común, provocación de inundaciones, tenencia, fabricación y tráfico de objetos peligrosos, y los tipos del capítulo de los delitos contra los recursos naturales y el ambiente:

Cuando el hecho punible sea imputable a la actividad de una persona jurídica o una sociedad de hecho, el juez competente, además de las sanciones de multa, cancelación de registro mercantil, suspensión temporal o definitiva de la obra o actividad, o cierre temporal o definitiva del establecimiento o de sus instalaciones, podrá imponer sanciones privativas de la libertad tanto a los representantes legales, directivos o funcionarios involucrados, por acción o por omisión, en la conducta delictiva.

\section{Sentencia C- 320 de 1998}

Esta sentencia fue proferida con motivo de las objeciones presidenciales respecto el artículo 26 del proyecto legislativo de la anterior norma, la Corte declaró infundada las objeciones y respaldó las sanciones penales a los entes colectivos sin hacerse mayores interrogantes. Por tanto se justificó la posibilidad legislativa de sancionar penalmente las actuaciones ilícitas de los entes colectivos sobre la base de: 
a. El legislador ha recibido en la Carta una amplia libertad para la configuración de su política sancionatoria, la cual puede trascender en ciertos supuestos del ámbito personal hasta los focos de poder.

b. Los administradores de las empresas deben evitar la violación de las normas penales y generar daños a la sociedad, pues cuando ello ocurre se está abusando de la personalidad jurídica, incurriendo los administradores en faltas graves que deben conducir no sólo a sanciones patrimoniales sino también penales.

c. Debe establecerse el nexo entre la conducta y la actividad de la empresa para llegar a las sanciones previstas.

d. Es necesario que la violación penal se haya cometido en el interés objeto de la persona jurídica o que esta haya reportado beneficio material del mismo.

e. La presunción que consagra la norma en contra las personas jurídicas, en todo caso admite prueba en contrario.

La decisión de la Corte Constitucional se enmarcó dentro del movimiento a favor de la responsabilidad penal de las personas jurídicas que refleja una tendencia a desdibujar la línea divisoria entre la responsabilidad civil y la penal. Las sociedades modernas parecen perder de vista que el castigo penal es un imperativo de justicia. A finales del siglo veinte, el sentido de la pena no se centra ya en la necesidad de expiar la culpabilidad sino en su utilidad práctica para influir en el comportamiento social. De este modo el argumento de que las personas jurídicas no son capaces de culpabilidad pierde peso cada día, y predomina la autoridad social a la hora de utilizar las armas que el derecho penal ofrece para disciplinar su comportamiento (Ibídem, p. 223).

\section{Sentencia C-843 de 1999}

En esta sentencia se declaró inexequible el artículo 26 de la ley 491 de 1999. Los motivos determinantes para ello se sustentaron en la violación del principio de legalidad. La Corte señaló:

1. La ley viola el principio de legalidad por desconocimiento del principio de taxatividad, la mera enunciación de sanciones penales, sin definir límites y 
elementos ciertos de aplicación de las distintas penas, viola el principio de legalidad, pues será el fallador, con criterios subjetivos, quien determine, con posterioridad la ocurrencia los hechos, cuál es la pena aplicable.

2. Igualmente, se considera que existe una cierta indeterminación del procedimiento que debe seguirse para sancionar a las personas jurídicas, pues la ley no prevé un procedimiento especial para tal efecto, y no es claro que pueda aplicarse integralmente y de manera inequívoca el procedimiento penal ordinario, designado básicamente para enjuiciar a las personas naturales. Para que pueda sancionarse penalmente a las personas jurídicas, no es suficiente que el Congreso defina los delitos y las penas imponibles sino que debe existir en el ordenamiento un procedimiento aplicable. El legislador debe al menos establecer unas normas que pueden ser poco numerosas, pero que sean suficientes para solucionar los interrogantes que suscita la aplicación a las personas jurídicas del procedimiento penal diseñado exclusivamente para enjuiciar a las personas naturales.

Por lo tanto, la Corte no cuestionó la posibilidad de sancionar penalmente a las personas jurídicas, por el contrario reafirmó la hipótesis de que "nada en la Constitución supone que la ley prevea, en ciertos casos, formas de responsabilidad penal de las personas jurídicas".

\section{Sentencia C-595 de 2010}

En esta sentencia la Corte Constitucional afirma que los principios de derecho penal se deben matizar para ser aplicados a las situaciones que involucren sanciones por afectaciones al ambiente, este es el caso de la responsabilidad objetiva, que está prohibida en el derecho penal.

Así pues, para la Corte la imposición de sanciones por responsabilidad objetiva se ajusta a la Constitución en la medida que (i) carezcan de la naturaleza de sanciones que la doctrina llama 'rescisorias', es decir, de sanciones que comprometen de manera específica el ejercicio de derechos y afectan de manera directa o indirecta a terceros; (ii) tengan un carácter meramente monetario y; (iii) sean de menor entidad en términos absolutos (tal como sucede en el caso de las sanciones de tránsito) o en términos relativos (tal como sucede en el régimen cambiario donde la sanción corresponde a un porcentaje del monto de la infracción o en el caso del decomiso 
en el que la afectación se limita exclusivamente a la propiedad sobre el bien cuya permanencia en el territorio es contraria a las normas aduaneras).

\section{Sentencia C-703 de 2010}

Para la Corte el catálogo de medidas de carácter sancionador en orden a proteger el medio ambiente no están regidos estrictamente por el derecho penal, así pues, los principios de legalidad, taxatividad y tipicidad de las sanciones, son fuente de inspiración para el derecho administrativo sancionador, pero son diferentes de los que rigen en esta área, por lo cual en el procedimiento administrativo no resulta viable exigir un rigor tan estricto como el que debe observarse en materia penal, y menos aún si ni siquiera en el ámbito mismo del derecho penal los principios que otrora se pretendían absolutos tienen ese carácter. Así pues, tratándose del medio ambiente resulta difícil garantizar la tradicional seguridad que es condición de las relaciones jurídicas, porque buena parte de las decisiones relacionadas con el medio ambiente se deben tomar en un marco complejo, difuso y esencialmente variable, circunstancias que llevan a que el derecho ambiental haya tenido que idear soluciones conducentes a la afinación de fórmulas propias que le otorgan una especial connotación a la intervención administrativa, siendo así que la exigencia de una clasificación detallada de infracciones administrativas en normas tipo, en donde no solo se haga una descripción exacta de la conducta que será objeto de sanción sino de la sanción misma, modelo típico del precepto penal, que devendría en el desconocimiento de la naturaleza misma de la actividad administrativa.

\section{Conclusiones}

En el sistema jurídico colombiano presente no es posible hablar de responsabilidad penal de las personas jurídicas cuando causan daños ambientales. A pesar de las normas sustantivas que han establecido tal posibilidad, los operadores del derecho se encuentran con insolubles problemas a la hora de investigar criminalmente la empresa, acusarla y condenarla como responsable de un delito, ya que tendrían que caer en un sistema de responsabilidad objetiva el cual está proscrito.

En primer lugar, la mayoría de empresas, son empresas transnacionales, lo que hace difícil la identificación de la jurisdicción aplicable, además 
generalmente estas empresas subcontratan muchos servicios, situación que hace difusa su responsabilidad.

Por otro lado, los principios de derecho penal deben ser olvidados para poder aplicar las sanciones, en razón a la complejidad del fenómeno criminal, los principios de legalidad, presunción de inocencia, debido proceso, responsabilidad personal y culpabilidad deben ser vulnerados, situación que hace difícil su juzgamiento porque las decisiones en contra de las empresas transnacionales se tornan inconstitucionales.

\section{Referencias}

Corte Constitucional de la República de Colombia. (2010). Sentencia C-703 del 2010. . (2010). Sentencia C-595 del 2010. . (1999). Sentencia C-843 del 1999. . (1998). Sentencia C-320 del 1998.

Corte Internacional de Justicia. (1949). Opinión Consultiva, Reparación de Perjuicios sufridos al servicio de las Naciones Unidas. Report.

Gilpin, R. (1990). Empresas Multinacionales y Producción Internacional. La economía politica de las relaciones internacionales. Grupo editor latinoamericano.

González-Tablas, A. (2000). Economía política de la globalización. Barcelona: Ariel.

Gracia, L. (2003). Prolegómenos para la lucha por la modernización y expansión del Derecho penal y para la crítica del discurso de resistencia. Valencia: Tirant lo Blanch.

Ramírez, Y. (2007). El delito ecológico. Bogotá: Temis.

Teitelbaum, A. (2007). Al margen de la Ley. Sociedades Transnacionales y derechos humanos. Bogotá: ILSA. 